\title{
Static secondary ion mass spectrometry (S-SIMS) for the characterization of surface components in mineral particulates
}

\author{
Rita Van Ham ${ }^{\mathrm{a}}$, Luc Van Vaeck ${ }^{\mathrm{a}}$, Annemie Adriaens ${ }^{\mathrm{b}, *}$, Freddy Adams ${ }^{\mathrm{a}}$, Brittany Hodges ${ }^{\mathrm{c}}$, \\ Anita Gianotto ${ }^{\mathrm{d}}$, Recep Avci ${ }^{\mathrm{e}}$, Anthony Appelhans ${ }^{\mathrm{d}}$, Gary Groenewold ${ }^{\mathrm{d}}$ \\ a Department of Chemistry, University of Antwerp, Universiteitsplein 1, B-2610 Antwerp, Belgium \\ b Department of Analytical Chemistry, Ghent University, Krijgslaan 281 - S12, B-9000 Ghent, Belgium \\ ${ }^{\mathrm{c}}$ Department of Chemistry, Purdue University, 560 Oval Drive, West Lafayette, IN 47907-2084, USA \\ ${ }^{\mathrm{d}}$ Chemistry Department, Idaho National Engineering and Environmental Laboratory, Idaho Falls, ID 83415-2208, USA \\ e Instrument and Chemical Analysis Laboratory, Department of Physics, Montana State University, Bozeman, MT 59717, USA \\ Received 13 July 2005; received in revised form 16 August 2005; accepted 3 September 2005 \\ Available online 20 October 2005
}

\begin{abstract}
The feasibility of static secondary ion mass spectrometry (S-SIMS) for the detection of molecule specific information from complex materials, such as natural clay and soil samples, has been investigated. Ion trap (IT), as well as triple quadrupole (TQ) instruments, have been used for mass analysis. Secondary ion images have been acquired using time-of-flight (TOF) S-SIMS. The generation of molecular adduct ions from thin and thick layers on the mineral substrates has been investigated using $\mathrm{KBr}$ as a simple model system. Results show that molecular adducts of $\mathrm{KBr}$ can be indeed detected from the spiked materials. However, the concentrations of the spiking solutions have to be significantly larger than expected from the surface area measured by gas adsorption techniques. In addition imaging analysis has evidenced that the detection of adduct ions in the mass spectra directly relates to the presence of local micro-crystallites.
\end{abstract}

(C) 2005 Elsevier B.V. All rights reserved.

Keywords: Static SIMS; Polyatomic ions; Speciation; Clay; Binary salts

\section{Introduction}

The adsorption of radionuclides on clay minerals is widely accepted as important for radioactive waste management. The natural availability of clays in large quantities, their sorption characteristics, low permeability and stability make clays very useful in controlling radionuclide concentrations in dumps.

Research at the Idaho National Engineering and Environmental Laboratory (INEEL) has been focused on the surface speciation of radionuclides in buried waste material. The contaminants can exist in a variety of chemical forms, which strongly influence their mobility in the environment and the choice of treatment approaches. In addition the interaction of a radionuclide with a specific mineral surface determines its sequestration or mobility in the heterogeneous environment. In order to better determine

\footnotetext{
* Corresponding author. Tel.: +32 9264 4826; fax: +32 92644960.

E-mail address: annemie.adriaens@ugent.be (A. Adriaens).
}

the risk from radionuclides in the available waste deposition site, previous research activities have involved the use of time of flight static secondary ion mass spectrometry (TOF S-SIMS) to identify the mineral phases at the surface of basalt [1] and the sorption of $\mathrm{Cs}^{+}$to soil particles by imaging the elemental composition [2].

The purpose of this paper is to explore the feasibility of SSIMS to obtain molecular information from the soil particle surfaces, ultimately allowing their modification water/cation infiltration to be investigated thereby contributing to an improved understanding of the adsorption and leaching processes. Molecular information refers to specification of the local composition of a sample in terms of molecules rather than elements. Depending on the analytical methodology used, the oxidation state of an element, the presence of specific bonds, or the entire molecule as a whole is characterized [3]. In this study we aim at the latter. Previous research has shown that S-SIMS has an excellent sensitivity, surface specificity and capability of molecular speciation through the detection of molecular (adduct) ions (i.e. 
analyte molecule attached to a stable ion) [3-10]. Additionally, the method can also generate spatially-resolved chemical information, which is valuable for the characterisation of heterogeneous samples [1,2,11-13].

This work makes use of $\mathrm{KBr}$ as a simple model system to delineate the feasibility of molecular speciation of inorganic compounds at the surface of clay materials. $\mathrm{KBr}$ was chosen as model system as its behaviour in S-SIMS as a pure compound has previously been investigated in detail $[3,4]$. The experimental strategy of the study involves the adsorption of $\mathrm{KBr}$ from aqueous solution with different concentrations on the clay or bulk fraction. After evaporation, the surface composition is analysed with S-SIMS to verify the surface coverage needed for molecular detection of $\mathrm{KBr}$. Additionally, the leaching properties of the different materials are investigated by washing spiked clays with water and S-SIMS analysis.

Three different instrumental set-ups have been used, including an ion trap (IT) SIMS equipped with a polyatomic $\mathrm{ReO}_{4}{ }^{-}$ ion gun, which is found to be suitable for the detection of intense signals from high $\mathrm{m} / \mathrm{z}$, adduct ions. However, mass spectra are frequently altered by the occurrence of ion molecule reactions occurring after the sputtering event [14]. Therefore, comparative analysis has been performed on an ion transport type analyzer using a triple quadrupole (TQ) mass filter using the same $\mathrm{ReO}_{4}{ }^{-}$ primary ion gun. A TOF-SIMS equipped with an atomic primary projectile $\left(\mathrm{Ga}^{+}\right)$has been used to obtain mass resolved images of the metal cations and spatially correlate contaminant and matrix ion signals.

\section{Experimental}

\subsection{Instrumentation}

Experiments were performed on an ion trap S-SIMS (a Finnigan ITMS modified for SIMS) [15] equipped with a solid-state ion source for the generation of perrhenate anions [16]. Polyatomic primary $\mathrm{ReO}_{4}{ }^{-}$ions were used with the energy of $5.5 \mathrm{keV}$ and a primary ion current of $570 \mathrm{pA}$. An area with a diameter of $2.5 \mathrm{~mm}$ was randomly hit, while the total ion dose was kept within $2 \times 10^{12}$ ions $\mathrm{cm}^{-2}$. The measurements were performed using a buffer gas pressure of $3.10^{-5} \mathrm{mbar}$, a leakage ring voltage of $+20 \mathrm{~V}$ and $-60 \mathrm{~V}$ for positive and negative ions, respectively, an ionisation time of $1-4 \mathrm{~ms}$ and $60 \mathrm{~ms}$ for positive and negative ions, respectively, a low mass cut-off between $\mathrm{m} / \mathrm{z}$ 15 and 35; and a delay time of $0 \mathrm{~ms}$. The mass range was scanned up to $m / z 600$.

Additional analyses were performed on a triple quadrupole S-SIMS (Extrel, Pittsburgh, PA) [17] using the same type of primary ion gun. The $\mathrm{ReO}_{4}{ }^{-}$gun is operated in the continuous mode and delivers about $180 \mathrm{pA}$ in a spot on the sample of $2.5 \mathrm{~mm}^{2}$. The mass range was scanned from $\mathrm{m} / z 5$ to 400 in steps of $0.2 \mathrm{amu}$ or $1 \mathrm{amu}$ and only the first quadrupole was used as a mass filter except for the MS-MS experiments. The latter were performed with Ar-gas in the central cell at a pressure of $5.6 \times 10^{-6} \mathrm{mbar}$. The resulting daughter ions were measured after the third quadrupole in the multiple ion-monitoring mode (parent ion, $\mathrm{Na}^{+}$and/or $\mathrm{K}^{+}$).
Imaging experiments were performed on a Charles Evans and Associates (Redwood City, CA, USA) TOF S-SIMS at the Image and Chemical Analysis Laboratory of the Montana State University (Bozeman, Montana, USA). The instrument uses three electrostatic sectors for mass analysis. A focused $\mathrm{Ga}^{+}(25 \mathrm{keV}$ and $600 \mathrm{pA}$ in dc mode) was rastered over $120 \mu \mathrm{m} \times 120 \mu \mathrm{m}$ during $4 \mathrm{~min}$. The total ion dose was $6.3 \times 10^{19}$ ions $\mathrm{cm}^{-2}$. The soil samples were pressed into Indium foil. A fully covered area was selected for analysis.

\subsection{Samples}

Soils samples were taken from the INEEL demonstration pit in a dedicated facility used as a permanent shallow-land disposal for low-level radioactive waste. The soil consists of slightly alkaline silt clay, containing predominantly aluminosilicates with high concentrations of calcium and magnesium carbonates near the surface. As to the mineral phases present, clay minerals such as illite, smectite, mixed illite smectite, 2:1 clays and some kaolinite have been identified whereas parent minerals consists of calcium carbonate, feldspars, quartz and diopsides. The cation exchange capacity is low and primarily related to the $\mathrm{Ca}^{2+}$ and $\mathrm{Mg}^{2+}$ ions. The clay was separated into a sand fraction $(>53 \mu \mathrm{m})$, the so-called "bulk" fraction $(2-53 \mu \mathrm{m})$, and the clay particles of less than $2 \mu \mathrm{m}$. Only the latter two fractions were used in this study.

The adsorption of $\mathrm{KBr}$ on the fractionated clay soil was achieved by mixing $150 \mathrm{mg}$ of soil with $1 \mathrm{~mL}$ of an aqueous salt solution. The $\mathrm{KBr}$ concentration was varied between $0.3 \mathrm{~g} \mathrm{~L}^{-1}$ and $100 \mathrm{~g} \mathrm{~L}^{-1}$. After stirring for $3 \mathrm{~h}$, the slurry was allowed to dry completely and the residue was ground. Samples for S-SIMS analysis were taken by tapping the sample support (a nail head for IT S-SIMS and a flattened wire for TQ S-SIMS) covered with double-sided tape.

In addition leaching experiments were performed on the clay samples. An aliquot of $2 \mathrm{~mL}$ distilled water (nanopure) was added to an amount of $50 \mathrm{mg}$ of clay samples, spiked before with solutions of $0.6-10 \mathrm{~g} \mathrm{~L}^{-1} \mathrm{KBr}$ and stirred for $1 \mathrm{~h}$. The slurry was centrifuged and the supernatant was removed. The procedure was repeated three times and the final residue was air-dried in the hood.

\section{Results and discussion}

\subsection{The untreated clay and bulk fraction}

Fig. 1 shows the positive ion mass spectra recorded with IT and TQ S-SIMS from the untreated clay fraction using similar $\mathrm{ReO}_{4}{ }^{-}$primary ion bombardment conditions. Most of the signals simply refer to atomic ions. The base peak is due to $\mathrm{Na}^{+}$ $(\mathrm{m} / \mathrm{z}, 23)$. As expected from an aluminosilicate, $\mathrm{Al}^{+}(\mathrm{m} / \mathrm{z} 227)$ and $\mathrm{Si}^{+}(\mathrm{m} / \mathrm{z} 28)$ yield predominant peaks while $\mathrm{Mg}^{+}(\mathrm{m} / \mathrm{z} 24)$ gives only a minor peak. The ions at $\mathrm{m} / \mathrm{z} 56$ are associated with $\mathrm{Fe}^{+}$and not with $\mathrm{CaO}^{+}$as a result of their relative abundance to $\mathrm{Ca}^{+}$in the mass spectrum. The abundant signal at $\mathrm{m} / \mathrm{z}, 19$ in the IT S-SIMS is due to $\mathrm{H}_{2} \mathrm{O} \cdot \mathrm{H}^{+}$as a result of memory effects. The instrument has been used before to study ion-molecule 

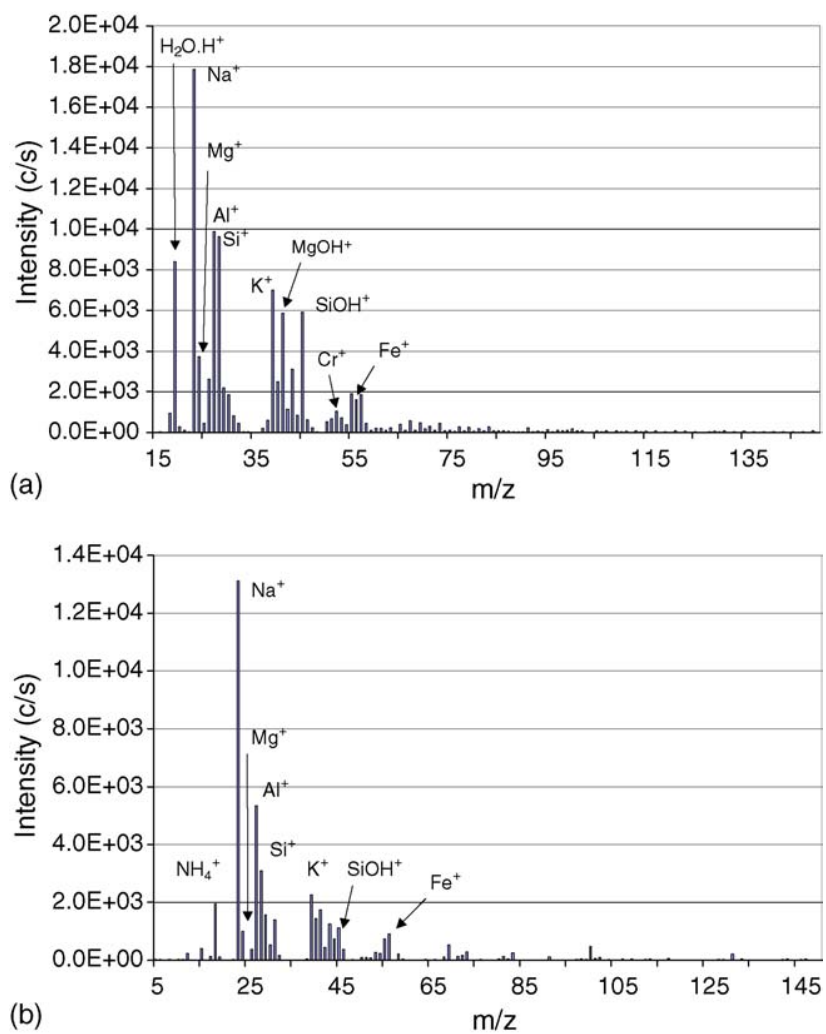

Fig. 1. Positive ion mass spectra from the untreated clay fraction measured with $\mathrm{ReO}_{4}{ }^{-}$primary ions using IT S-SIMS (a) and TQ S-SIMS (b).

interactions with water. The presence of the $\mathrm{Cr}^{+}$signal $(\mathrm{m} / \mathrm{z}$ $52)$ is due to the stainless steel grid in front of the sample. Also the $\mathrm{Fe}^{+}$ions $(\mathrm{m} / \mathrm{z}, 56)$ can be due to this grid but only in part since they are also found in the TQ S-SIMS (without a grid). Molecular information is only confined to the protonated $\mathrm{MgOH}^{+}(m / z 41)$ and $\mathrm{SiOH}^{+}(m / z 45)$ as a fragment.

In contrast to the cations, anions yield molecular information. There are essentially two types of mass spectra, depending on the presence or absence of intense signals related to phosphates. Fig. 2 shows representative examples and Table 1 summarizes the assignment of anions above $m / z$ 100. In the phosphate free case, the main signals refer to the silicate component in the form of $\mathrm{SiO}_{2}{ }^{-}(\mathrm{m} / \mathrm{z}, 60), \mathrm{SiO}_{3}{ }^{-}(\mathrm{m} / \mathrm{z}, 76)$ and $\mathrm{HSiO}_{3}{ }^{-}(\mathrm{m} / \mathrm{z}$

Table 1

Assignments of the peaks in Fig. 2

\begin{tabular}{ll}
\hline Ion & $\mathrm{m} / z$ \\
\hline $\mathrm{CrO}_{3}$ & 100 \\
$\mathrm{Al}_{2} \mathrm{O}_{3} \cdot \mathrm{OH}$ & 119 \\
$\mathrm{Al}_{2} \mathrm{O}_{3} \cdot \mathrm{H}_{2} \mathrm{O} \cdot \mathrm{OH}$ & 137 \\
$\mathrm{Al}_{2} \mathrm{O}_{3} \cdot\left(\mathrm{H}_{2} \mathrm{O}\right)_{2} \cdot \mathrm{OH}$ & 155 \\
$\left(\mathrm{SiO}_{2}\right)_{2} \cdot \mathrm{HSiO}$ & 197 \\
$\mathrm{SiO}_{3} \cdot \mathrm{SiO}_{2} \cdot \mathrm{PO}_{3}$ & 215 \\
$\mathrm{H}_{2} \mathrm{SiO}_{3} \cdot \mathrm{SiO}_{2} \cdot \mathrm{PO}_{3}$ & 217 \\
$\left(\mathrm{H}_{2} \mathrm{SiO}_{3}\right)_{2} \cdot \mathrm{PO}_{2}$ & 219 \\
$\left(\mathrm{H}_{2} \mathrm{SiO}_{3}\right)_{2} \cdot \mathrm{HSiO}_{3}$ & 233 \\
$\left(\mathrm{H}_{2} \mathrm{SiO}_{3}\right)_{2} \cdot \mathrm{H}_{2} \mathrm{O} \cdot \mathrm{SiO}_{2}$ & 234 \\
$\mathrm{H}_{2} \mathrm{SiO}_{3} \cdot \mathrm{HPO}_{3} \cdot \mathrm{HSiO}_{3}$ & 235 \\
$\left(\mathrm{H}_{2} \mathrm{SiO}_{3}\right)_{2} \cdot \mathrm{H}_{2} \mathrm{O} \cdot \mathrm{SiO}_{3}$ & 250 \\
\hline
\end{tabular}
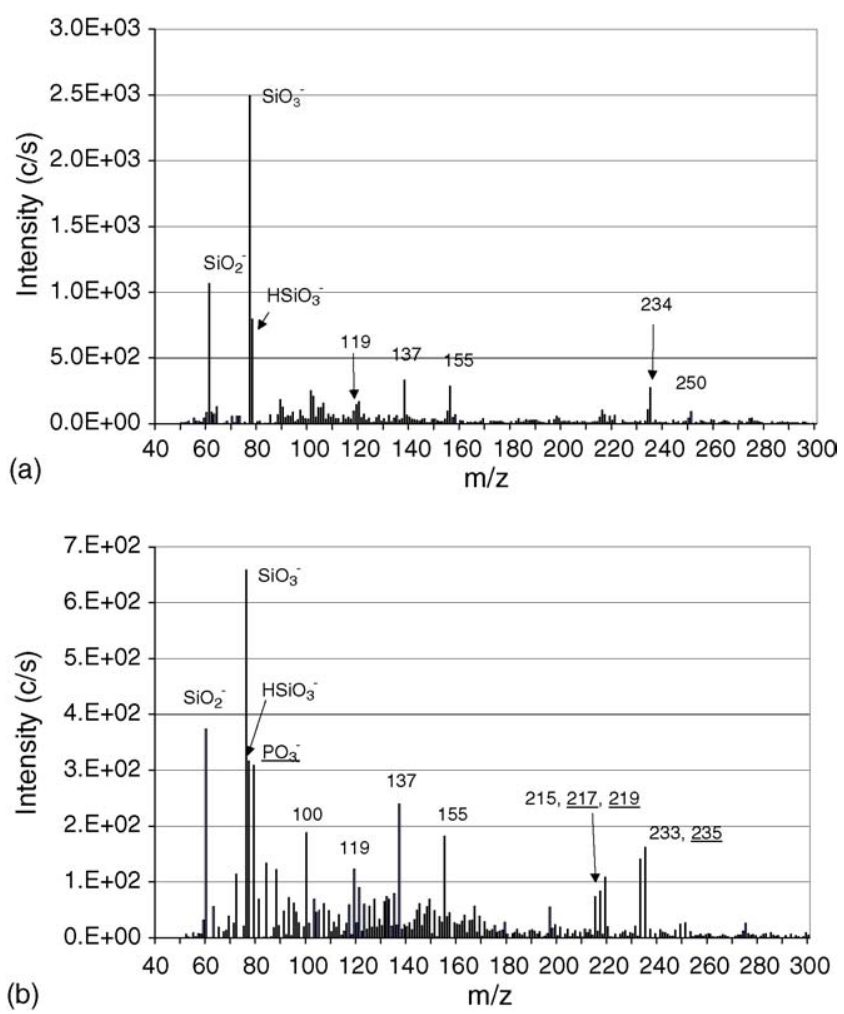

Fig. 2. Typical negative ion spectra recorded from the untreated clay fraction using IT S-SIMS under $\mathrm{ReO}_{4}{ }^{-}$bombardment. Spectrum (a) characterises a phosphate free blank; spectrum (b) a phosphate rich blank. The assignment of the ions above $m / z, 100$ is given in Table 1 .

77) accompanied by molecular adducts of $\mathrm{HSiO}_{3}{ }^{-}$to one or several molecules of $\mathrm{SiO}_{2}, \mathrm{H}_{2} \mathrm{O}$ or $\mathrm{H}_{2} \mathrm{SiO}_{3}$. Additionally, the aluminium oxide component of the clay is indicated by the ions at $\mathrm{m} / \mathrm{z}, 119$ assigned to $\mathrm{Al}_{2} \mathrm{O}_{3} \cdot \mathrm{OH}^{-}$. The alternative possibility of $\mathrm{SiO}_{2} \cdot \mathrm{AlO}_{2}{ }^{-}$is rejected because of the small intensity of $\mathrm{AlO}_{2}{ }^{-}$ at $m / z$ 59. This explanation is consistent with the data reported by Scott et al. [14]. The same line of reasoning is followed to assign the peaks at $\mathrm{m} / \mathrm{z}, 137$ and 155 to $\mathrm{SiO}_{2}$ based ions instead of to $\mathrm{Al}_{2} \mathrm{O}_{3} \cdot \mathrm{H}_{2} \mathrm{O} \cdot \mathrm{OH}^{-}\left(\mathrm{m} / \mathrm{z}\right.$ 137) and $\mathrm{Al}_{2} \mathrm{O}_{3} \cdot\left(\mathrm{H}_{2} \mathrm{O}\right)_{2} \cdot \mathrm{OH}^{-}(\mathrm{m} / \mathrm{z}$ 155). The other type of clay blank spectrum contains intense $\mathrm{PO}_{x}{ }^{-}$peaks, of which the $\mathrm{PO}_{3}{ }^{-}$at $\mathrm{m} / z 79$ prevails. Additional evidence for phosphates arise through the signals at $m / z 217,219$ and 235, which consists of the $\mathrm{OH}^{-}$attached to neutrals such as $\mathrm{SiO}_{2}, \mathrm{H}_{2} \mathrm{O}\left(\right.$ or $\left.\mathrm{H}_{2} \mathrm{SiO}_{3}\right)$ and $\mathrm{HPO}_{3}$. At the same time, the series of $\mathrm{SiO}_{2}$ based adducts extends to higher $\mathrm{m} / \mathrm{z}$ than in the case of a phosphate free clay blank sample.

Positive ion mass spectra of untreated bulk fraction are very similar to those of the clay fraction, whereas anions give a typical pattern of phosphate free clay.

\subsection{Adsorption of KBr on the clay and bulk fraction}

Fig. 3 shows the typical positive and negative ion mass spectra recorded by TQ S-SIMS from the clay fraction exposed to a $\mathrm{KBr}$ solution of $100 \mathrm{~g} \mathrm{~L}^{-1}$. Apart from the base peak due to $\mathrm{K}^{+}$ $(\mathrm{m} / \mathrm{z}, 39)$, cations produce prominent signals from mono- and dimeric adducts (i.e. attachment of a stable ion to one or two 

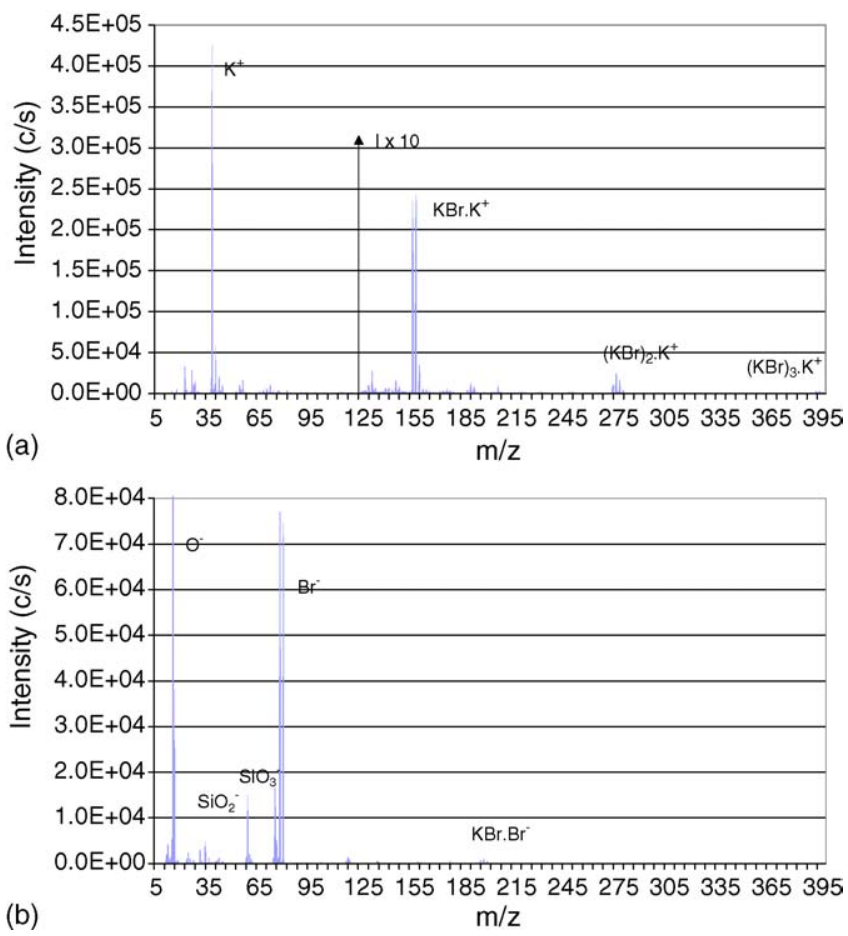

Fig. 3. Positive (a) and negative (b) ion mass spectra from the clay fraction spiked with a $100 \mathrm{~g} \mathrm{~L}^{-1} \mathrm{KBr}$ solution and measured with TQ S-SIMS under $\mathrm{ReO}_{4}{ }^{-}$bombardment.

neutral molecules $\mathrm{KBr}$ ), while the trimers are just visible. Negative ion mass spectra essentially contain the $\mathrm{Br}^{-}(\mathrm{m} / \mathrm{z} 79$ and 81) and $\mathrm{KBr} \cdot \mathrm{Br}^{-}(m / z, 197-201)$ signals to characterize the added salt. In fact, the general appearance of the data is reminiscent to pure $\mathrm{KBr}$ with only a small contribution from the "blank" ions (e.g. $\mathrm{Al}^{+}$is about $6 \%$ of $\mathrm{K}^{+}$). The IT S-SIMS results agree very well with those recorded on the TQ S-SIMS except for the $\mathrm{KBr}^{-}$molecular anions that are virtually absent in the IT S-SIMS.

In order to describe the adsorption experiment more quantitatively, the use of normalised intensities for atomic ions and monomeric adducts has been considered. The underlying principle idea is that the former ratio allows the exchange of $\mathrm{Na}^{+}$by $\mathrm{K}^{+}$at the surface to be assessed, while the relative adduct intensities are more appropriate to verify the presence of molecules or aggregates at the surface. A different type of normalisation has been required depending on the type of instrument used. In IT S-SIMS, for instance, the low mass cut-off limits the $\mathrm{m} / \mathrm{z}$ range to be considered. Positive ions are referenced to the sum of the signals at $\mathrm{m} / z 45\left(\mathrm{SiOH}^{+}\right), 52\left(\mathrm{Cr}^{+}\right.$from the grid), $56\left(\mathrm{Fe}^{+}\right.$from the grid and the clay) and $79\left(\mathrm{H}_{2} \mathrm{SiO}_{3} \cdot \mathrm{H}^{+}\right)$. For the negative ions, the sum of $\mathrm{SiO}_{2}{ }^{-}(\mathrm{m} / \mathrm{z} 60), \mathrm{SiO}_{3}{ }^{-}(\mathrm{m} / \mathrm{z} 76)$ and $\mathrm{SiO}_{2} \cdot \mathrm{OH}^{-}(\mathrm{m} / \mathrm{z}$ 77 ) is taken. Fig. 4 summarizes the main information obtained. The trend lines fitting the normalized intensities of adduct ions show a steep increase for samples, prepared from the solution with the highest concentration. Application of the gas adsorption method to this clay fraction has yielded an active area of $95 \mathrm{~m}^{2} \mathrm{~g}^{-1}$. Considering the use of $150 \mathrm{mg}$ of clay with an active area of $1.4 \times 10^{19} \mathrm{~nm}^{2}$ and estimating that the area of a $\mathrm{KBr}$ molecule is $0.28 \mathrm{~nm}^{2}, 1 \mathrm{~mL}$ solution containing $10 \mathrm{~g} \mathrm{~L}^{-1}$ con-

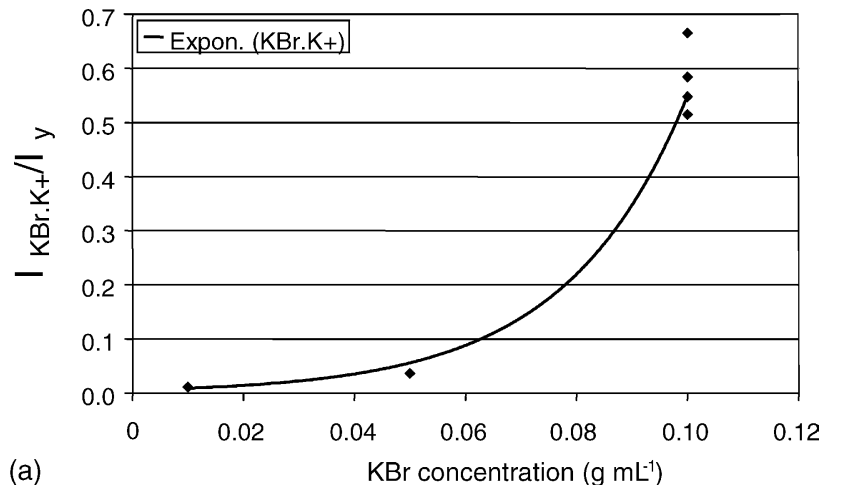

(a)

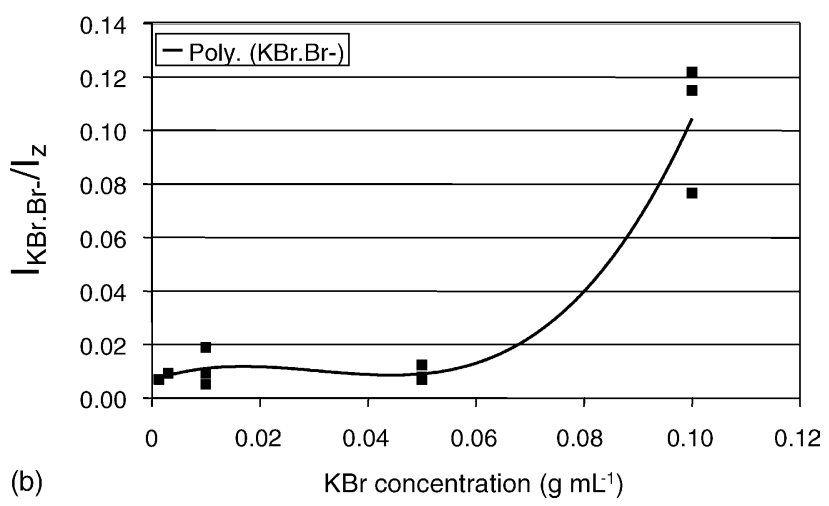

Fig. 4. Dependence of the normalised adduct positive (a) and negative (b) ion intensities in IT S-SIMS mass spectra of the spiked clay fraction as a function of the $\mathrm{KBr}$ concentration $\left(\mathrm{g} \mathrm{mL}^{-1}\right) . I_{\mathrm{y}}$ stands for the sum of $\mathrm{SiOH}^{+}(\mathrm{m} / z 45), \mathrm{Cr}^{+}$ $(m / z 52), \mathrm{Fe}^{+}(\mathrm{m} / z 56)$ and $\mathrm{H}_{2} \mathrm{SiO}_{3} \cdot \mathrm{H}^{+}(\mathrm{m} / z 79)$ signals. $I_{\mathrm{z}}$ stands for the sum of $\mathrm{SiO}_{2}{ }^{-}(m / z, 60), \mathrm{SiO}_{3}{ }^{-}(m / z, 76)$ and $\mathrm{SiO}_{2} \cdot \mathrm{OH}^{-}(m / z, 77)$ signals.
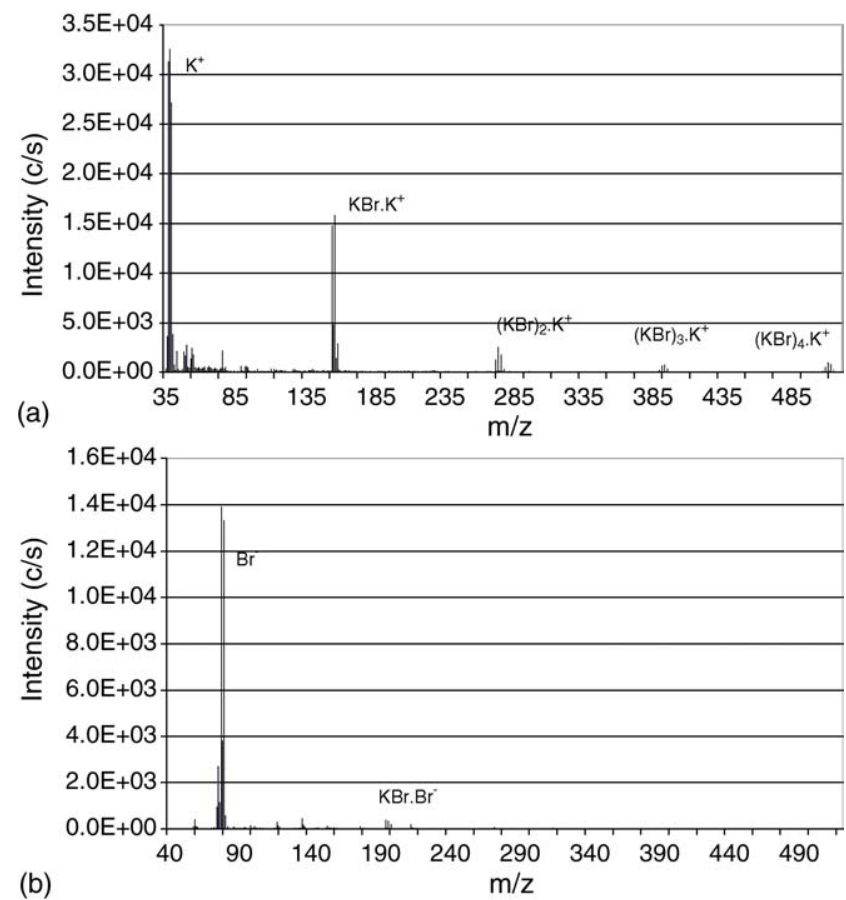

Fig. 5. Positive (a) and negative (b) ion mass spectra from the bulk fraction spiked with a $100 \mathrm{~g} \mathrm{~L}^{-1} \mathrm{KBr}$ solution and measured with IT S-SIMS under $\mathrm{ReO}_{4}{ }^{-}$bombardment. 
tains already sufficient $\mathrm{KBr}$ to cover the clay completely with one monolayer.

The mass spectra recorded from the bulk fraction exposed to a solution containing $100 \mathrm{~g} \mathrm{~L}^{-1}$ again correspond to a superposition of the $\mathrm{KBr}$ peak pattern as a dominant contribution over the ions seen in the blank. As seen in Fig. 5, the positive adduct ions with up to 4 neutral molecules are present with a significantly higher signal to noise ration than in the case of the clay sample (cf. Fig. 3). The data for the anions are comparable to the ones obtained from the clay samples. Again the characteristic intensity ratio of $\mathrm{K}^{+}$and $\mathrm{KBr} \cdot \mathrm{K}^{+}$over the summed matrix ions $\left(\mathrm{SiOH}^{+}, \mathrm{Cr}^{+}, \mathrm{Fe}^{+}\right.$and $\left.\mathrm{H}_{2} \mathrm{SiO}_{3} \cdot \mathrm{H}^{+}\right)$exhibits a steep increase from
$50 \mathrm{~g} \mathrm{~L}^{-1}$ onwards. Even the absolute values of the normalized peak intensities are similar to those for the clay samples, in spite of the different surface area in the size-fractionated material. Specifically, the specific area measured by the gas adsorption method for the bulk is $32 \mathrm{~m}^{2} \mathrm{~g}^{-1}$ (versus $95 \mathrm{~m}^{2} \mathrm{~g}^{-1}$ for the clay).

In conclusion, the onset of adduct ion detection from $\mathrm{KBr}$ ad layers requires exposure of the mineral material to salt concentrations that are much higher than expected for a monolayer coverage. Furthermore, there is no clear distinction to be made as a function of the specific area, composition or surface properties. Otherwise stated, it looks like thick multi-layers or local surface precipitates are needed to detect monomeric
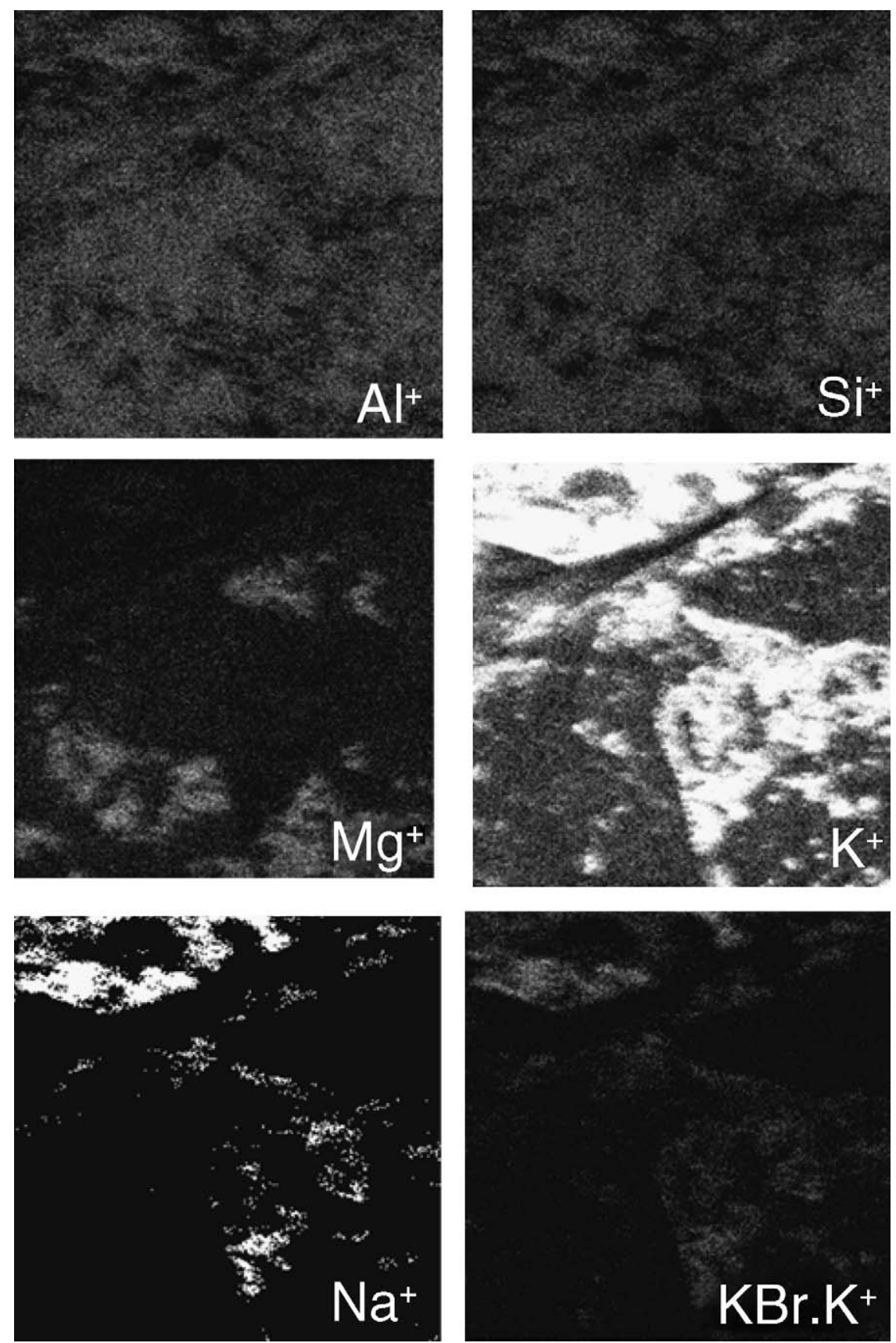

Fig. 6. Secondary ion images of $\mathrm{Al}^{+}(\mathrm{m} / \mathrm{z} 27), \mathrm{Si}^{+}(\mathrm{m} / \mathrm{z} 28), \mathrm{K}^{+}(\mathrm{m} / \mathrm{z} 39), \mathrm{Mg}^{+}(\mathrm{m} / \mathrm{z} 24), \mathrm{Na}^{+}(\mathrm{m} / \mathrm{z} 23)$ and $\mathrm{KBr} \cdot \mathrm{K}^{+}\left(\mathrm{m} / \mathrm{z}\right.$ 157) generated by Ga${ }^{+}$primary ion bombardment in TOF S-SIMS over an area of $120 \mu \mathrm{m} \times 120 \mu \mathrm{m}$ from the clay fraction spiked with a $100 \mathrm{~g} \mathrm{~L}^{-1}$ solution of $\mathrm{KBr}$. 


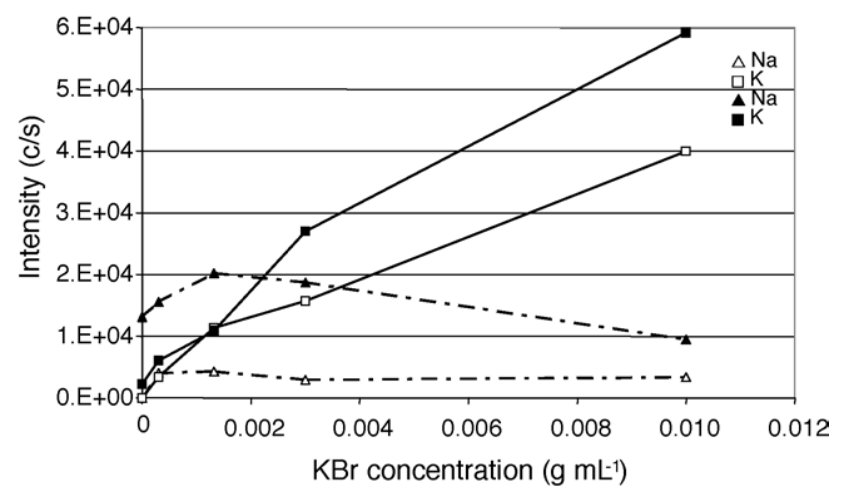

Fig. 7. Variation of the peak intensities as a function of the $\mathrm{KBr}$ concentration in solution $\left(\mathrm{g} \mathrm{mL}^{-1}\right)$ used for initial spiking of the clay fraction measured with TQ S-SIMS. The filled symbols refer to spiked samples before leaching and the open symbols to the material after leaching.

adducts. This idea has been confirmed by images recorded over a $120 \mu \mathrm{m} \times 120 \mu \mathrm{m}$ area by TOF S-SIMS. Fig. 6 shows the uniform distribution of $\mathrm{Al}^{+}$and $\mathrm{Si}^{+}$as expected for matrix ions. In contrast, $\mathrm{K}^{+}$and $\mathrm{Mg}^{+}$provide complementary images which confirm that divalent cations are not exchanged for monovalent ones. Both $\mathrm{Na}^{+}$and $\mathrm{K}^{+}$seem to be enriched in the same regions but not in the same spots. The formation of local "microcrystallites" (or stacked $\mathrm{KBr}$ layers) is confirmed by the images of $\mathrm{KBr} \cdot \mathrm{K}^{+}$.

\subsection{Leaching of $\mathrm{KBr}$ adsorped on clay}

Only the samples exposed to solutions with a low concentration have been used in the leaching experiments as it is irrelevant to study the removal of micro-crystallites at the surface. However, this limits the useful signals to the elemental ions. Fig. 7 displays the change in absolute intensities for $\mathrm{Na}^{+}$and $\mathrm{K}^{+}$before and after leaching. Untreated clay is characterized by a signal intensity ratio for $\mathrm{Na}^{+} / \mathrm{K}^{+}$of about 6 . Washing leads to the inverse situation in that the signal of $\mathrm{K}^{+}$is more intense than that of $\mathrm{Na}^{+}$. Exposure to low concentrations $\left(<1.6 \mathrm{~g} \mathrm{~L}^{-1}\right)$ of $\mathrm{KBr}$ and subsequent washing evidently removes the initial $\mathrm{Na}^{+}$while it has little effect on the $\mathrm{K}^{+}$content. The latter implies that the bond between $\mathrm{K}^{+}$and the soil is much stronger than the one between $\mathrm{Na}^{+}$and the soil.

\section{Conclusions}

This work has aimed at exploring the application of S-SIMS to obtain molecular information of the surface components in a complex material such as clay and soil samples.

Within the framework of a research project at the INEEL on the characterisation of soils from a radioactive waste dump, $\mathrm{KBr}$ has been selected as a simple model to probe the capabilities of S-SIMS for molecular speciation of surface components in such soil materials. Clay (particle fraction $2-53 \mu \mathrm{m}$ ) and so-called bulk material (particles $>53 \mu \mathrm{m}$ ) have been exposed to solutions containing different concentrations of $\mathrm{KBr}$ and the residue after evaporation has been characterised. Additional leaching experiments have been conducted.

It has been demonstrated that molecular adducts of $\mathrm{KBr}$ can be indeed detected from the spiked materials. However, the concentrations of the spiking solutions have to be significantly larger than expected from the surface area measured by gas adsorption techniques. Imaging analysis has evidenced that the detection of adduct ions in the mass spectra directly relates to the presence of local micro-crystallites. Leaching experiments have shown the preferential removal of $\mathrm{Na}^{+}$from the surface, suggesting that the binding of $\mathrm{K}$ to $\mathrm{Br}$ is stronger.

\section{Acknowledgements}

This work was supported in part by the Belgian Office for Scientific, Technical and Cultural Affairs (IUAP 5) and by FWO, Brussels, Belgium (research projects G.0090.98 and G.0172.00). R. Van Ham is indebted to the FWO for a travel grant to INEEL.

\section{References}

[1] J.C. Ingram, G.S. Groenewold, J.E. Olson, A.K. Gianotto, M.O McCurry, Anal. Chem. 71 (1999) 1712.

[2] G.S. Groenewold, J.C. Ingram, T. McLing, A.K. Gianotto, R. Avci, Anal. Chem. 70 (1998) 534.

[3] R. Van Ham, L. Van Vaeck, F. Adams, A. Adriaens, Anal. Chem. 76 (2004) 2609.

[4] R. Van Ham, A. Adriaens, L. Van Vaeck, R. Gijbels, F. Adams, Nucl. Instrum. Meth. B 161-163 (2000) 245.

[5] L. Van Vaeck, A. Adriaens, R. Gijbels, Mass Spectrom. Rev. 18 (1999) 1.

[6] A. Adriaens, A.R. Van Ham, L. Van Vaeck, Fundamental aspects of inorganic SIMS, in: J. Vickerman, D. Briggs (Eds.), TOF-SIMS: Surface Analysis by Mass Spectrometry, IM Publications, Chichester, UK, and SurfaceSpectra, Manchester, 2001, p. 195.

[7] R. Van Ham, L. Van Vaeck, A. Adriaens, F. Adams, B. Hodges, G. Groenewold, J. Anal. Atom. Spectrom. 17 (8) (2002) 753.

[8] R. Van Ham, L. Van Vaeck, F. Adams, A. Adriaens, Anal. Chim. Acta 500 (2003) 259

[9] R. Van Ham, L. Van Vaeck, F. Adams, A. Adriaens, J. Anal. At. Spectrom. 20 (2005) 1088.

[10] R. Van Ham, L. Van Vaeck, A. Adriaens, F. Adams, B. Hodges, A. Appelhans, G. Groenewold, Int. J. Mass Spectrom. 247 (2005) 28.

[11] B.W. Schueler, Microsc. Microanal. Microstruct. 3 (1992) 119.

[12] K.G. Stowe, S.L. Chryssoulis, J.Y. Kim, Miner. Eng. 8 (1995) 421.

[13] G.S. Groenewold, A.K. Gianotto, J.E. Olson, A.D. Appelhans, J.C. Ingram, J.E. Delmore, A.D. Shaw, Int. J. Mass Spectrom. 174 (1998) 129.

[14] J.R. Scott, G.S. Groenewold, A.K. Gianotto, M.T. Benson, J.B. Wright, J. Phys. Chem. A 104 (2000) 7079.

[15] G.S. Groenewold, A.D. Appelhans, J.C. Ingram, J. Am. Soc. Mass Spectrom. 9 (1998) 35.

[16] J.E. Delmore, A.D. Appelhans, E.S. Peterson, Int. J. Mass Spectrom. Ion Proc. 146-147 (1995) 15.

[17] G.S. Groenewold, J.E. Delmore, J.E. Olson, A.D. Appelhans, J.C. Ingram, D.A. Dahl, Int. J. Mass Spectrom. Ion Proc. 163 (1997) 185. 